\title{
Robot-assisted gait training for stroke patients: current state of the art and perspectives of robotics
}

This article was published in the following Dove Press journal:

Neuropsychiatric Disease and Treatment

15 May 2017

Number of times this article has been viewed

\section{Giovanni Morone 1,2 \\ Stefano Paolucci ${ }^{1,2}$ \\ Andrea Cherubini ${ }^{3}$ \\ Domenico De Angelis' \\ Vincenzo Venturiero' \\ Paola Coiro' \\ Marco losa ${ }^{1,2}$ \\ 'Private Inpatient Unit, ${ }^{2} \mathrm{Clinical}$ Laboratory of Experimental Neurorehabilitation, IRCCS Santa Lucia Foundation, Rome, Italy; ${ }^{3}$ Department of Robotics, LIRMM UM-CNRS, Montpellier, France}

\section{Video abstract}

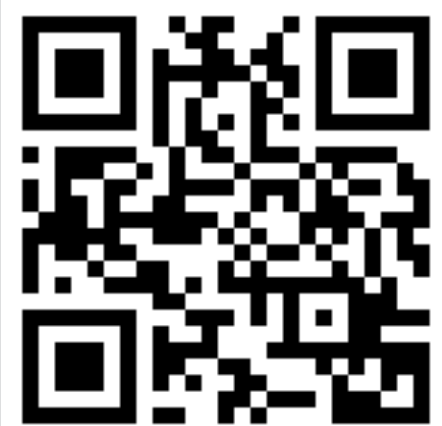

Point your SmartPhone at the code above. If you have a QR code reader the video abstract will appear. Or use: http://youtu.be/m7WBZpqYwWc

Correspondence: Stefano Paolucci Private Inpatient Unit, IRCCS Santa Lucia Foundation, Via Ardeatina 306-354, 00179 Rome, Italy

Tel +39065150 1001

Fax +39065I501004

Email s.paolucci@hsantalucia.it
Abstract: In this review, we give a brief outline of robot-mediated gait training for stroke patients, as an important emerging field in rehabilitation. Technological innovations are allowing rehabilitation to move toward more integrated processes, with improved efficiency and less longterm impairments. In particular, robot-mediated neurorehabilitation is a rapidly advancing field, which uses robotic systems to define new methods for treating neurological injuries, especially stroke. The use of robots in gait training can enhance rehabilitation, but it needs to be used according to well-defined neuroscientific principles. The field of robot-mediated neurorehabilitation brings challenges to both bioengineering and clinical practice. This article reviews the state of the art (including commercially available systems) and perspectives of robotics in poststroke rehabilitation for walking recovery. A critical revision, including the problems at stake regarding robotic clinical use, is also presented.

Keywords: exoskeleton, neurorehabilitation, robot-assisted walking training, wearable robot, activities of daily living, motor learning, plasticity

\section{Introduction}

Stroke is a leading cause of movement disability in the US and Europe. ${ }^{1}$ By 2030 , it has been estimated that there could be as many as 70 million stroke survivors around the world. ${ }^{2}$ The proportion of patients achieving independence by 1 year after a stroke ranges from $\sim 60 \%$ to $83 \%$ in self-care and between $10 \%$ and $15 \%$ in a residential clinical institution. ${ }^{3}$ Concerning mobility recovery, a 2008 study showed that $\sim 50 \%$ of patients with stroke leave the rehabilitation hospital on a wheelchair, $<15 \%$ are able to walk indoor without aids, $<10 \%$ are able to walk outdoor, and $<5 \%$ are able to climb stairs. ${ }^{4}$ Poststroke rehabilitation demand will increase in the near future, leading to stronger pressure on health care budgets. For example, in the US, the estimated direct and indirect cost of stroke in 2010 was $\$ 73.7$ billion, and the mean lifetime cost of ischemic stroke was estimated at $\$ 140.048 .^{5}$ For ethical reasons, in adjunction to these economical reasons, an increase of rehabilitation efficacy is mandatory. New technologies, early discharge after intensive training, and home rehabilitation are among the innovations proposed for achieving this. Current literature suggests that rehabilitative interventions are more effective if they ensure early, intensive, task-specific, and multisensory stimulation, with both bottom-up and top-down integration, favoring brain plasticity. ${ }^{6,7}$ In fact, there is growing evidence that the motor system is plastic following stroke and that motor training can be of aid, particularly in the first 3 months. ${ }^{8}$ Neuroplasticity can lead to recovery mechanisms and functional adaptation resulting from global changes 


\section{Rehabilitative determinants of walking robotic training}

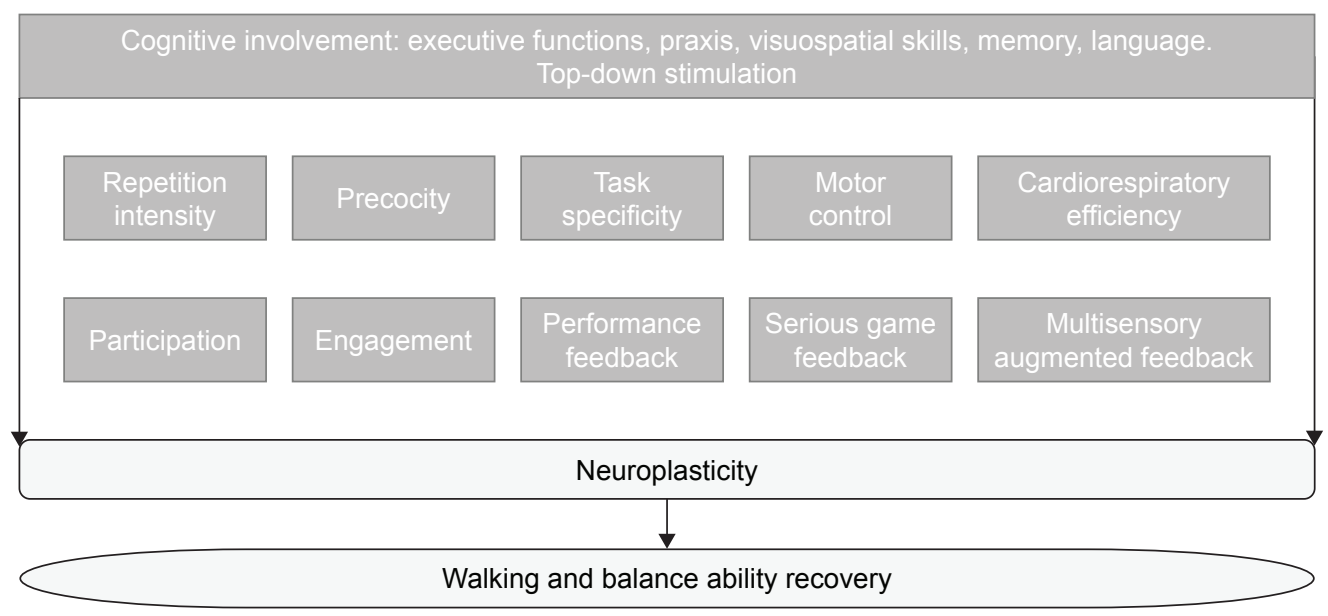

Figure I The determinants of gait and balance by multisystem rehabilitation of patients with stroke who may benefit from robotic training.

in neuronal organization. It is associated with changes in excitatory/inhibitory balance as well as the spatial extent and activation of cortical maps and structural remodeling. ${ }^{9,10}$

In this scenario, the emerging field of robotic rehabilitation needs to be integrated with the neurological principles supporting the scientific evidences that a robot may improve specific abilities of neurological patients. Figure 1 shows the determinants of gait rehabilitation of patients with stroke that may benefit from robotic training, including those related to other technologies such as serious video games and augmented biofeedback.

This review aims to exploit, by following user-centered principles, the clinical efficacy of robotic devices and enhance their role in the next generation of rehabilitation protocols.

\section{Machines for walking rehabilitation}

A complete review of all the machines developed worldwide is very difficult to achieve because of the number of prototypes tested within the scientific community.

First, it is necessary to clarify the difference between a robot and other electromechanical devices. The Robot Institute of America defines a robot as

a programmable, multi-functional manipulator designed to move material, parts or specialized devices through variable programmed motions for the performance of a variety of tasks. ${ }^{11}$

Hence, in contrast with the popular - and erroneousperception (which includes, eg, kitchen aids), a robot is by definition capable of mobility, with various levels of autonomy.
Based on this definition, an incomplete list of commercial robot walk trainers includes the following: Gait Trainer (RehaStim, Berlin, Germany), G-EO (Reha Technology AG, Olten, Switzerland), Lokomat (Hocoma, Volketswil, Switzerland), Bionic Leg (Tibion Bionic Technologies, Moffett Field, CA, USA), eLEGS (University of California Berkeley/Ekso Bionics, Richmond, CA, USA), ReWalk (Argo Medical Technologies, Yokneam, Israel), and REX (Rex Bionics, Auckland, New Zealand). Another list may include prototypes not yet fully commercialized, such as Lopes, Lopes 2 (developed at the University of Twente, Enschede, the Netherlands), Knexo (Vrije University Brussel, Ixelles, Belgium), Alex (University of Delaware, Newark, NJ, USA), Mindwalker (Delft University, Delft, the Netherlands), VanderBilt Exoskeleton (VanderBilt University, Nashville, TN, USA), Hercule (CEA-LIST/ RB3D, Paris, France), i-Walker (Universitat Politècnica de Catalunya, Barcelona, Spain), Walkbot (P\&S Mechanics Co, Ltd, Seoul, South Korea), Walk Assist Robot (Toyota, Tokyo, Japan), Honda's walking assist device (Honda, Tokyo, Japan), Anklebot (Massachusetts Institute of Technology, Cambridge, MA, USA), and Indego (Parker Hannifin Corporation, El Segundo, CA, USA). ${ }^{7,12-14}$

These devices can be classified according to the motion they apply to the patient's body. For instance, “exoskeletons" move joints, such as hip, knee, and ankle, controlled during the gait phases, whereas "end-effector robots" move only the feet, often placed on a support (footplate), which imposes specific trajectories, simulating the stance and swing phases during gait training. ${ }^{15}$ Another possible classification 


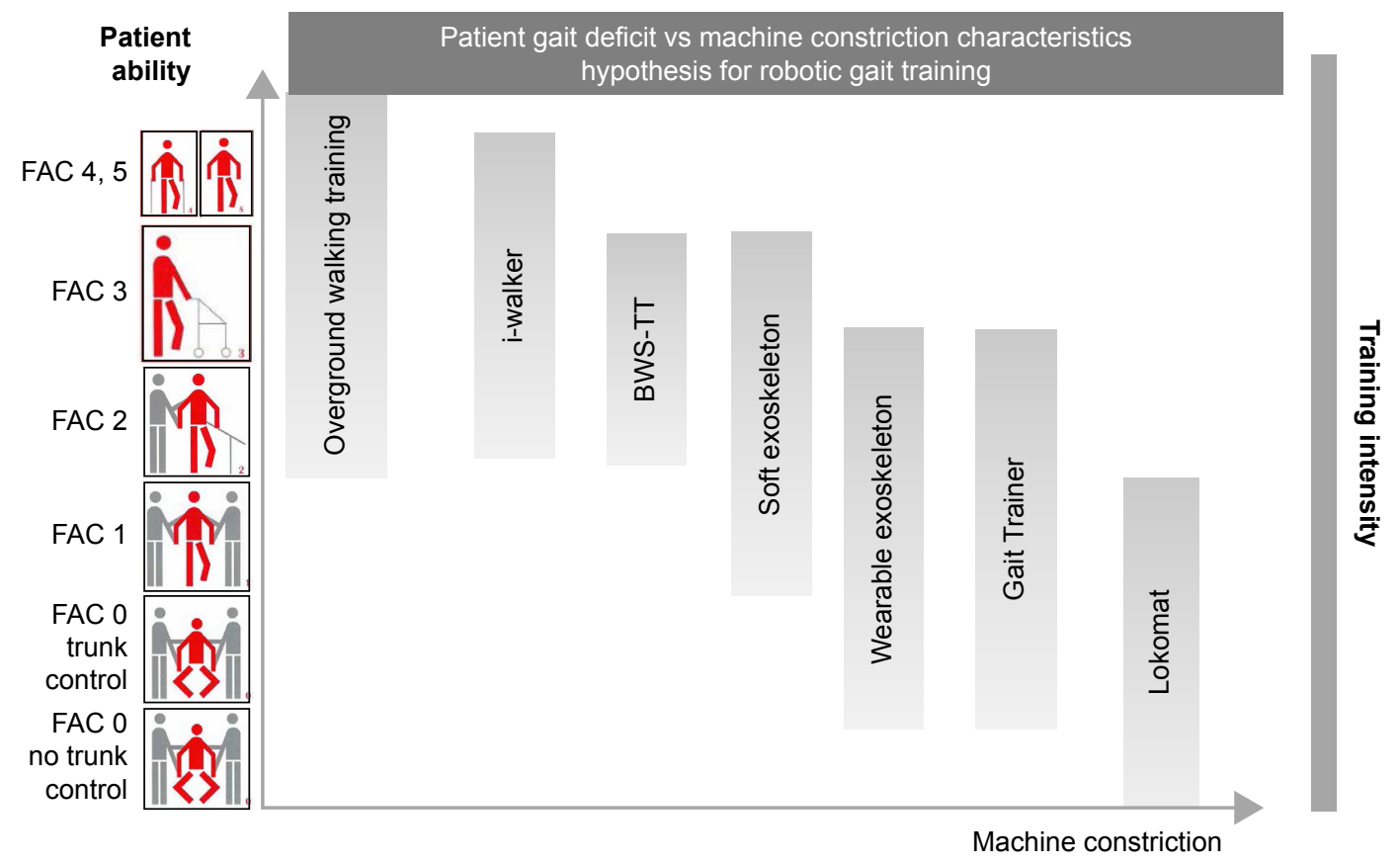

Figure 2 Theoretical schema combining patient's level of ability defined by functional classification of ambulation (FAC) with best possible solution in terms of walking training and machine constriction.

Abbreviation: BWS-TT, body weight-supported treadmill training.

is between devices in which the patient is moved in a fixed place and those moving the patient around the environment. We could define these devices as static and dynamic ones, respectively (Figure 2).

Among static devices, ie, devices designed for performing motion in place, and not around the environment, the most common ones are the Lokomat, which is a robotic exoskeleton, and the Gait Trainer and G-EO, these last two being end effectors.

Lokomat $^{16}$ is a robotic gait orthosis combined with a harness-supported body weight system, used in combination with a treadmill. The main difference with treadmill training with body weight support is that the patient's leg joints are guided according to a preprogrammed gait kinematic pattern.

Gait Trainer is based on a double crank and rocker gear system. In contrast with treadmills, it consists of two footplates positioned on two bars, two rockers, and two cranks, which provide the propulsion. The footplates symmetrically generate the stance and swing phases. ${ }^{17}$ The main difference with treadmill training with body weight support is that feet are always in contact with the platform, moving the feet for simulating the gait phases.

G-EO System ("eo" comes from Latin for "I go") is based on the end-effector principle and was designed to minimize the therapeutic effort needed for relearning walking and also stair climbing. The trajectories of the footplates as well as the vertical and horizontal movements of the center of mass are fully programmable. ${ }^{18}$

In recent years, extensive research efforts have been dedicated to dynamic exoskeletons for neurorehabilitation, as well as military applications (eg, to augment the soldiers' walking functions). Robotic hip-knee-ankle-foot exoskeletal orthoses have become commercially available and may help poststroke patients to stand and walk again. These devices also have applications beyond mobility, eg, exercise, amelioration of secondary complications related to lack of ambulation, and promotion of neuroplasticity. Wearable exoskeletons are recently developed technologies that allow walking even on a hard flat surface. ${ }^{12}$

Exoskeletons incorporate the actuators that move the patient's legs during the gait cycle, through a preprogrammed and near-normal gait cycle. ${ }^{19}$ Preliminary results showed the possibility of performing individual walking training in patients with subacute and chronic stroke. ${ }^{19}$

Almost all functional exoskeletons rely on additional support aids to ensure balance. Healthy users would perform proper foot placement and other actions to ensure balance stability. However, impaired people would need additional devices such as crutches.

New findings in neuroscience and translational researches from animal models showed that neurorehabilitation requires the following: increasing the therapy dosage and intensity, ${ }^{20}$ high repetitiveness, ${ }^{21}$ task-oriented exercises, ${ }^{22}$ 
and combination of top-down and bottom-up approaches (eg, noninvasive brain stimulation with robot therapy). ${ }^{23}$

As aforementioned, the best time for boosting plasticitydependent recovery is within 3 months from the stroke event. On the other hand, animal models have shown that increased therapy within 5 days from the stroke can enlarge brain damage and favor spasticity. ${ }^{23}$

Robotic systems are well suited to produce intensive, task-oriented motor training for moving the patient's limbs under the supervision/help of a therapist, as part of an integrated set of rehabilitation tools that would include other new devices as well as simpler and more traditional ones. ${ }^{15,24,25}$ In this context, robots would enhance conventional poststroke rehabilitation via intense and task-oriented training.

\section{Theoretical and practical robotic support for gait rehabilitation}

A common feature of gait training robots is the possibility to support (partially or totally) the body weight and the movement of patients. Body weight support seems to be the condition sine qua non for facilitating gait recovery with robotic devices. ${ }^{26}$ To restore gait, clinicians prefer a taskspecific repetitive approach and, in recent years, better outcomes have been achieved with higher intensities of walking practice programs. ${ }^{27-29}$ Another role of robotic devices is to facilitate the administration, to nonambulatory patients, of intensive and highly repetitive training of complex gait cycles, something a single therapist cannot easily do alone. With respect to treadmill training with partial body weight support, yet another advantage of these robotic devices may be the reduced effort for therapists: they no longer need to set the paretic limbs or assist trunk movements. ${ }^{30}$ A secondary but important feature related to body weight support and to robotic rehabilitation in general is the possibility of favoring the restoration of an adequate level of cardiorespiratory efficiency. Despite this aspect being rarely taken into account in evaluating robotic efficiency, ${ }^{31}$ previous results have shown that robotic gait training reduces energy consumption and cardiorespiratory load. In fact, for severely impaired neurological patients, robotic walk training allows an early verticalization without the risk of increasing spasticity on antigravitational muscles, hence avoiding deconditioning, which would worsen cardiologic comorbidities. This is a very important feature, if one considers that cardiovascular disease is the leading prospective cause of death in people with chronic stroke. ${ }^{32}$ It is well known that persons with stroke suffer an extremely poor cardiovascular fitness, with a reduction of the mobility and a consequent reduction of the quality of life..$^{33}$
Energy consumption and cardiorespiratory load during walking with robot assistance seems to depend not only on body weight support but also on factors such as robot type, walking speed, and amount of effort. These parameters could be adjusted during robotic rehabilitation to make it either more or less energy consuming and stressful for the cardiorespiratory system. ${ }^{34}$

\section{Robotic rehabilitation "versus" or "together" with physiotherapy?}

A recently updated Cochrane revision of 23 trials involving 999 participants showed that robotic gait training combined with physiotherapy might improve recovery of independent walking in poststroke patients. In particular, people in the first 3 months after stroke and those who are not able to walk seem to benefit most from this type of intervention. This review also highlighted that determining the frequency, duration, and timing (after stroke) for the robotic gait training to be the most effective is still an open problem. Assessing the benefit duration also requires further research. ${ }^{35}$

The use of robots should not replace the neurorehabilitation therapy performed by a physiotherapist. Robots, as all technological devices, must be considered as tools in the hands of the physiotherapist and never rehabilitative per se. ${ }^{36}$ In fact, the robot can alleviate all labor-intensive phases of physical rehabilitation, hence allowing the physiotherapist to focus on functional rehabilitation during individual training and to supervise several patients at the same time during robotassisted therapy sessions. With this approach, the expertise and time of physiotherapists is optimized, increasing the rehabilitation program's efficacy and efficiency at the same time. ${ }^{37}$

With respect to conventional therapy alone, the addition of robotic intervention brings another important advantage: it allows an online and offline instrumented, quantitative (hence, objective) evaluation of several parameters related to patient performance. These include range of motion, velocity, smoothness of movements, amount of forces, and so on. Thus, robotic systems may be used not only to produce simple and repetitive stereotyped movement patterns, as in the case of most of the existing devices, but also to generate a more complex, controlled multisensory stimulation of the patient. This includes, but is not limited to, the assessment of the patient's performance with a biofeedback or with a report.

A recent review, inspired by Isaac Asimov's famous three laws of robotics and based on the most recent studies in neurorobotics, proposed three similar laws valid for neurorehabilitation robots. The objective was to propose guidelines for designing and using such robots. ${ }^{38}$ These laws 
were driven by the ethical need for safe and effective robots, by the redefinition of their role as therapist helpers, and by the need for clear and transparent human-machine interfaces. The three laws are as follows:

1. a neurorobot shall not injure a patient or let him/her come to harm;

2. a neurorobot must obey the therapist's orders, except if such order is in conflict with the First Law;

3. a neurorobot must adapt its behavior to the patients' abilities in a transparent way, except if this is in conflict with the First or Second law.

Although the first law may seem obvious, in the study by Iosa et al, ${ }^{38}$ the term "harm" has been redefined to include all possible damage to patients, including time wasted on an ineffective, inefficient, or even detrimental robot. In fact, many robots have been commercialized without proving their quality. Hence, this law implies that robot usage should be at least as safe and effective as other treatments, implying that it should have a higher benefit-to-risk ratio than conventional treatments.

The second law recalls that neurorobots are, in the first place, tools in the hands of therapists, just as medical robots for surgeons. Robots should "disobey" clinicians' orders only if their sensors highlight that a potential risk for the patient can be provoked by that order. This highlights the importance of sensors, which is at the base of the adaptability and autonomy of any robotic system.

This last aspect is reinforced in the third law, which claims the importance of artificial intelligence as a support for human intelligence, with real-time adaptation to the continuously monitored and measured patient's ability.

An aspect rarely taken into account in robotic rehabilitation is the psychology of the patient, who often needs not only to be cured, but also to be cared. It is well known that patients' engagement and participation in conventional exercises is considered a key factor to increase rehabilitation performances and thereby boost plasticity. ${ }^{39}$ During robot-assisted therapy, this can be achieved via extrinsic feedback of serious game scenarios, where the scores obtained assess the patients' performance. ${ }^{40}$ The acceptance of robotic technology by patients and physiotherapists may be an issue per se, although there is no evidence of this for the devices developed to date. Nevertheless, not all patients, especially the elderly, accept to be treated with a robot, and Bragoni et $\mathrm{al}^{41}$ have shown that anxiety may reduce the efficacy of robotic walking training. In the future, the cultural gap among technology providers, rehabilitation professionals, and end users should be filled by improving the dissemination of technological knowledge and the diffusion of increasingly user-friendly and safer technology.

\section{From "efficacy for all" to "all for efficacy"}

Most studies on walking neurorehabilitation robots focus on their effectiveness, giving controversial results. For instance, Mehrholz and Pohl ${ }^{42}$ showed that patients who receive robotassisted gait training in combination with physiotherapy achieve independent walking more easily than patients trained without these devices. However, clinical trials suggest that manual therapy may still be more effective than robotic gait training in both subacute and chronic phases. ${ }^{43,44}$ The reason may be a reduction in voluntary postural control during robot-assisted gait training, often due to constraints presented by robots, with the passive swing assistance provided by the robotic system used in the studies. ${ }^{43}$

In the complex scenario of gait recovery robots, it is fundamental to understand the clinical meaning of each design feature, such as body weight support, especially for training nonambulatory patients in an intensive and safe manner. ${ }^{41}$

Both end effectors and exoskeleton robotic devices have their own strengths and weaknesses. It is, therefore, important to consider the rationale of the two types of devices and the related benefits or disadvantages of each.

In particular, end-effector walking devices allow the patient to extend his/her knee with more freedom. In addition, the task of maintaining balance may be more demanding (since the required degree of balance depends on the harness setup and on whether or not the patient is holding the hand rails). An advantage of exoskeletons is that gait cycles can be controlled more easily. We are not aware of any studies directly comparing different devices for gait rehabilitation in patients with a cerebral damage, with the exception of a single case report. ${ }^{45}$

Interestingly, these two robotic solutions train patients in two different ways in terms of constriction/freedom of patients' ability. For this reason, they should not be seen as alternative, but complementary: each one represents the best option for a specific kind of patient impairment.

It is important to understand how different robotic approaches will respond to different rehabilitation problems and patients (Figure 3), as well as to all users' (patients, therapists, and clinicians) needs in general. As affirmed recently by Cochrane, ${ }^{35}$ it is imperative to define the characteristics of patients who may benefit the most from robotic therapy. According to the principle that overground training is the 


\begin{tabular}{|l|l|l|l|l|}
\hline $\begin{array}{l}\text { Robotic devices } \\
\text { (examples) }\end{array}$ & "Static" (training in place) & Lokomat \\
\hline Exoskeletons & Gait Trainer & "Dynamic" \\
\hline End effectors & &
\end{tabular}

Figure 3 Examples of robotic devices with different approaches.

most physiological one, although not always possible, the more is the severity of stroke, the more should be the help and the constraint level provided by the device, as shown in Figure 2.

Most studies aim at answering the question "are robotic devices effective for all kinds of poststroke patients?". However, Morone et $\mathrm{al}^{46}$ have highlighted the need for changing this question into "for whom are robotic devices the most effective?" The goal should not be to test the efficacy for all patients but to dispose of all the possibilities, for improving efficacy. For instance, the least-affected patients would rather benefit from device-free conventional overground training than use artificial interventions that may alter recovery of their physiological patterns. ${ }^{46}$

A key point for the diffusion and correct use of new technologies is to know the group of patients for whom and the rehabilitation phase during which each type of technology is more beneficial. Following this principle, Morone et a $1^{46,47}$ found that patients with more severe motor leg impairments are those who benefit the most from robot-assisted therapy in combination with conventional therapy. This finding probably results from the augmented intensity of robotic therapy, as compared to conventional therapy (especially for the most impaired patients). Conversely, patients with greater voluntary motor function in the affected limb can perform intensive training during conventional therapy also. A large rehabilitation study (Locomotor Experience Applied Post-Stroke [LEAPS] ${ }^{48}$ showed that more expensive high-tech therapy was not superior to intensive home strength and balance training (the so-called kitchen sink exercises), but both were better than lower-intensity physical therapy. These results may support the idea that the great advantage of robots designed for walking therapy is only related to the warranty of a more intensive therapy. Consequently, after 20 years of investigation on robotic devices, including body weight support systems, efficacy is still uncertain, and most of the robotic use is still confined to research-controlled trial instead of in clinical practice. ${ }^{49}$ This skepticism has led to put into question the clinical usability of robots in neurorehabilitation: Hidler and Lum $^{50}$ questioned the possibility that these devices will become commonplace in every hospital and rehabilitation clinic or whether they will become things of the past like so many other promising prototypes. In addition, Iosa et al, ${ }^{15}$ after having asked "Where are the robots promised by scientific literature able to restore motor functions after stroke?", noted that despite surgical robots being introduced at around the same time as rehabilitation robots, only the benefit of the formers has been well established. ${ }^{38}$

On the other hand, from a theoretical point of view, many researchers agree that patients may benefit from machines providing external support, until they recover the capacity of walking over ground, unsupported. Robots can favor this recovery, allowing a progressive decrease of external support matching the patients' level of gait dependency. ${ }^{46}$ Probably, the question needs to be changed from "Are robotic devices 
effective for rehabilitation?" to "Who may benefit the most from robotic rehabilitation"?

\section{Current perspective and open problems}

According to the current literature, it is not yet clear how different rehabilitation approaches contribute to restorative processes of the central nervous systems after stroke. In this scenario, the efficacy of robotic gait training seems to be strictly related to a good identification of the best candidates among patients of those who could benefit more from a robotic training. This choice is strictly related to both physical ${ }^{46}$ and psychological ${ }^{41,51}$ features with respect to the available devices.

A promising approach is the combination of different technologies, where each one facilitates the other. This is the case of a brain-controlled neuromuscular stimulation coupled to an exoskeleton ${ }^{52}$ or of noninvasive brain stimulation (transcranial direct current stimulation [tDCS] and transcranial magnetic stimulation [TMS]) associated with robotic training. ${ }^{53,54}$ However, noninvasive brain stimulation associated with robots yielded limited results, ${ }^{55,56}$ unless the parameters were properly tuned according to the candidate patients. ${ }^{57}$

There are also some other points deserving attention. Despite most studies claiming that robots would increase rehabilitation intensity, repetition of tasks alone is not sufficient to guide neural plasticity. ${ }^{58}$ Furthermore, most robots replicate physiological patterns, not always reachievable by patients. The approach is analogous to training footballers only to play many matches, without focusing the training on specific aspects and exercises that need to be improved separately. In fact, optimal schemes of robot assistance to facilitate motor skill learning are debated. ${ }^{59}$ Thus, a robot is not a substitute for physical therapists but should be considered a tool in the hands of therapists to train different determinants of a multisystem rehabilitation and for improving patients' skills. ${ }^{60}$ This leads to the need for a robot of active onboard control algorithms combined with functional motor learning tasks, to improve participation, required assistance, and reinforcement learning. ${ }^{61}$

\section{Conclusion}

Finally, most of the robots commercialized nowadays are based on the a priori idea that walking is an automatic subcortical ability. However, this aspect was recently reconsidered from the following perspectives: 1) from a biomechanical point of view, by reviewing the role of the trunk from a passive ${ }^{62}$ to an active actor; ${ }^{63} 2$ ) from a neurological point of view, in which the conventional bottom-up approach has been integrated in a top-down approach; $;{ }^{64} 3$ ) from a neuromechanical point of view, in which structures and functions are strictly connected around specific harmonic points of equilibrium that maximize the efficiency of walking. ${ }^{65,66}$

At this step, the role of the clinical researcher is to investigate whether the available robot is effective or not for the level of severity in patients with stroke admitted to his/her rehabilitation hospital. The role of bioengineers should be to match the most recent neurological findings with the specifics of the robots developed for gait training, not only simulating physiological patterns and emulating the therapist, but favoring and widening the determinants of gait recovery. Finally, both clinicians and bioengineers should collaborate for defining new paradigms and protocols for increasing robotic effectiveness and diffusion within the rehabilitation teams.

\section{Disclosure}

The authors have no relevant affiliation or financial involvement with any organization or entity with a financial interest in or financial conflict with the subject, matter, or materials discussed in the manuscript. This includes employment, consultancies, honoraria, stock ownership or options, expert testimony, grants, or patents, received or pending, or royalties. The authors report no conflicts of interest in this work.

\section{References}

1. Rosamond W, Flegal K, Furie K, et al. Heart disease and stroke statistics-2007 update: a report from the American heart association statistics committee and stroke statistics subcommittee. Circulation. 2007;115(5):e69-e171.

2. Feigin VL, Forouzanfar MH, Krishnamurthi R, et al. Global and regional burden of stroke during 1990-2010: findings from the Global Burden of Disease Study 2010. Lancet. 2014;383(9913):245-254

3. Appelros P, Nydevik I, Viitanen M. Poor outcome after first-ever stroke: predictors for death, dependency, and recurrent stroke within the first year. Stroke. 2003;34(1):122-126.

4. Paolucci S, Bragoni M, Coiro P, et al. Quantification of the probability of reaching mobility independence at discharge from a rehabilitation hospital in nonwalking early ischemic stroke patients: a multivariate study. Cerebrovasc Dis. 2008;26(1):16-22.

5. Lloyd-Jones D, Adams RJ, Brown TM, et al; Writing Group Members; American Heart Association Statistics Committee and Stroke Statistics Subcommittee. Heart disease and stroke statistics - 2010 update: a report from the American Heart Association. Circulation. 2010; 121(7):46-215.

6. Belda-Lois JM, Mena-del Horno S, Bermejo-Bosch I, et al. Rehabilitation of gait after stroke: a review towards a top-down approach. J Neuroeng Rehabil. 2011;8:66.

7. Masiero S, Poli P, Rosati G, et al. The value of robotic systems in stroke rehabilitation. Expert Rev Med Devices. 2014;11(2):187-198.

8. Wolpert DM, Diedrichsen J, Flanagan JR. Principles of sensorimotor learning. Nat Rev Neurosci. 2011;12(12):739-751. 
9. Huber D, Gutnisky DA, Peron S, et al. Multiple dynamic representations in the motor cortex during sensorimotor learning. Nature. 2012; 484(7395):473-478.

10. Nudo RJ. Postinfarct cortical plasticity and behavioral recovery. Stroke. 2007;38(2):840-845.

11. Xie M. Fundamental of Robotics: Linking Perception to Action. Singapore: World Scientific; 2003.

12. Chen $\mathrm{G}, \mathrm{Chan} \mathrm{CK}, \mathrm{Guo} \mathrm{Z}, \mathrm{Yu} \mathrm{H}$. A review of lower extremity assistive robotic exoskeletons in rehabilitation therapy. Crit Rev Biomed Eng. 2013;41(4-5):343-363. Review.

13. Morone G, Annicchiarico R, Iosa M, et al. Overground walking training with the $\mathrm{i}-\mathrm{Walker}$, a robotic servo-assistive device, enhances balance in patients with subacute stroke: a randomized controlled trial. J Neuroeng Rehabil. 2016;13(1):47.

14. Wang S, Meijneke C, van der Kooij H. Modeling, design, and optimization of Mindwalker series elastic joint. IEEE Int Conf Rehabil Robot. 2013;2013:6650381

15. Iosa M, Morone G, Fusco A, et al. Seven capital devices for the future of stroke rehabilitation. Stroke Res Treat. 2012;2012:187965.

16. Colombo G, Joerg M, Schreier R, Dietz V. Treadmill training of paraplegic patients using a robotic orthosis. J Rehabil Res Dev. 2000; 37(6):693-700.

17. Schmidt H, Werner C, Bernhardt R, Hesse S, Krüger J. Gait rehabilitation machines based on programmable footplates. J Neuroeng Rehabil. 2007;9(4):2

18. Hesse S, Waldner A, Tomelleri C. Research innovative gait robot for the repetitive practice of floor walking and stair climbing up and down in stroke patients. $J$ Neuroeng Rehabil. 2010;7:30.

19. Molteni F, Gasperini G, Gaffuri M, et al. Wearable robotic exoskeleton for over-ground gait training in sub-acute and chronic hemiparetic stroke patients: preliminary results. Eur J Phys Rehabil Med. Epub 2017 Jan 24

20. Nelles G. Cortical reorganization - effects of intensive therapy. Restor Neurol Neurosci. 2004;22(3-5):239-244.

21. Butefisch C, Hummelsheim H, Denzler P, Mauritz KH. Repetitive training of isolated movements improves the outcome of motor rehabilitation of the centrally paretic hand. J Neurol Sci. 1995;130(1):59-68.

22. Bayona NA, Bitensky J, Salter K, Teasell R. The role of task-specific training in rehabilitation therapies. Top Stroke Rehabil. 2005;12(3): $58-65$.

23. Krakauer JW, Carmichael ST, Corbett D, Wittenberg GF. Getting neurorehabilitation right: what can be learned from animal models? Neurorehabil Neural Repair. 2012;26(8):923-931.

24. Johnson MJ, Feng X, Johnson LM, Winters JM. Potential of a suite of robot/computer-assisted motivating systems for personalized, homebased, stroke rehabilitation. J Neuroeng Rehabil. 2007;4:6.

25. Dobkin BH. Strategies for stroke rehabilitation. Lancet Neurol. 2004; 3(9):528-536

26. Iosa M, Morone G, Bragoni M, et al. Driving electromechanically assisted Gait Trainer for people with stroke. J Rehabil Res Dev. 2011; 48(2):135-146.

27. French B, Thomas L, Leathley M, et al. Does repetitive task training improve functional activity after stroke? A Cochrane systematic review and meta-analysis. J Rehabil Med. 2010;42(1):9-14.

28. Wevers L, van de Port I, Vermue M, Mead G, Kwakkel G. Effects of task-oriented circuit class training on walking competency after stroke: a systematic review. Stroke. 2009;40(7):2450-2459.

29. Van de Port IG, Wood-Dauphinee S, Lindeman E, Kwakkel G. Effects of exercise training programs on walking competency after stroke: a systematic review. Am J Phys Med Rehabil. 2007;86(11):935-951.

30. Hesse S, Mehrholz J, Werner C. Robot-assisted upper and lower limb rehabilitation after stroke: walking and arm/hand function. Dtsch Arztebl Int. 2008;105(18):330-336.

31. Delussu AS, Morone G, Iosa M, Bragoni M, Traballesi M, Paolucci S Physiological responses and energy cost of walking on the Gait Trainer with and without body weight support in subacute stroke patients. J Neuroeng Rehabil. 2014;11:54.
32. Roth EJ. Heart disease in patients with stroke: incidence, impact, and implications for rehabilitation. Part I: classification and prevalence. Arch Phys Med Rehabil. 1993;74(7):752-760.

33. Ryan AS, Dobrovolny L, Silver K, Smith GV, Macko RF. Cardiovascular fitness after stroke: role of muscle mass and gait deficit severity. J Stroke Cerebrovasc Dis. 2000;9(4):185-191.

34. Lefeber N, Swinnen E, Kerckhofs E. The immediate effects of robotassistance on energy consumption and cardiorespiratory load during walking compared to walking without robot-assistance: a systematic review. Disabil Rehabil Assist Technol. 2016;20:1-15.

35. Mehrholz J, Elsner B, Werner C, Kugler J, Pohl M. Electromechanicalassisted training for walking after stroke. Cochrane Database Syst Rev. 2013;7:CD006185.

36. Morone G, Masiero S, Werner C, Paolucci S. Advances in neuromotor stroke rehabilitation. Biomed Res Int. 2014;2014:236043.

37. Kahn LE, Lum PS, Rymer WZ, Reinkensmeyer DJ. Robot-assisted movement training for the stroke-impaired arm: does it matter what the robot does? J Rehabil Res Dev. 2006;43(5):619-630.

38. Iosa M, Morone G, Cherubini A, Paolucci S. The three laws of neurorobotics: a review on what neurorehabilitation robots should do for patients and clinicians. J Med Biol Eng. 2016;36:1-11. Review.

39. Sathian K, Buxbaum LJ, Cohen LG, et al. Neurological principles and rehabilitation of action disorders: common clinical deficits. Neurorehabil Neural Repair. 2011;25(5 suppl):21S-32S

40. Van Vliet PM, Wulf G. Extrinsic feedback for motor learning after stroke: what is the evidence? Disabil Rehabil. 2006;28(13-14):831-840.

41. Bragoni M, Broccoli M, Iosa M, et al. Influence of psychologic features on rehabilitation outcomes in patients with subacute stroke trained with robotic-aided walking therapy. Am J Phys Med Rehabil. 2013;92(10 supp1 2):e16-e25.

42. Mehrholz J, Pohl M. Electromechanical-assisted gait training after stroke: a systematic review comparing end-effector and exoskeleton devices. J Rehabil Med. 2012;44(3):193-199.

43. Hornby TG, Campbell DD, Kahn JH, Demott T, Moore JL, Roth HR. Enhanced gait-related improvements after therapist- versus roboticassisted locomotor training in subjects with chronic stroke: a randomized controlled study. Stroke. 2008;39(6):1786-1792.

44. Hidler J, Nichols D, Pelliccio M, et al. Multicenter randomized clinical trial evaluating the effectiveness of the Lokomat in subacute stroke. Neurorehabil Neural Repair. 2009;23(1):5-13.

45. Regnaux JP, Saremi K, Marehbian J, Bussel B, Dobkin BH. An accelerometry-based comparison of 2 robotic assistive devices for treadmill training of gait. Neurorehabil Neural Repair. 2008;22(4): 348-354.

46. Morone G, Iosa M, Bragoni M, et al. Who may have durable benefit from robotic gait training? A 2-year follow-up randomized controlled trial in patients with subacute stroke. Stroke. 2012;43(4):1140-1142.

47. Morone G, Bragoni M, Iosa M, et al. Who may benefit from robotic-assisted gait training? A randomized clinical trial in patients with subacute stroke. Neurorehabil Neural Repair. 2011;25(7): 636-644.

48. Duncan PW, Sullivan KJ, Behrman AL, et al. LEAPS Investigative Team. Body-weight-supported treadmill rehabilitation after stroke. N Engl J Med. 2011;364(21):2026-2036.

49. Dobkin BH, Duncan PW. Should body weight-supported treadmill training and robotic-assistive steppers for locomotor training trot back to the starting gate? Neurorehabil Neural Repair. 2012;4: 308-317.

50. Hidler J, Lum PS. The road ahead for rehabilitation robotics. J Rehabil Res Dev. 2011;48(4):vii-X.

51. Calabrò RS, De Cola MC, Leo A, et al. Robotic neurorehabilitation in patients with chronic stroke: psychological well-being beyond motor improvement. Int J Rehabil Res. 2015;38(3):219-225.

52. Grimm F, Walter A, Spüler M, Naros G, Rosenstiel W, Gharabaghi A. Hybrid neuroprosthesis for the upper limb: combining brain-controlled neuromuscular stimulation with a multi-joint arm exoskeleton. Front Neurosci. 2016;10:367. 
53. Straudi S, Fregni F, Martinuzzi C, Pavarelli C, Salvioli S, Basaglia N. tDCS and robotics on upper limb stroke rehabilitation: effect modification by stroke duration and type of stroke. Biomed Res Int. 2016;2016:5068127.

54. Buetefisch C, Heger R, Schicks W, Seitz R, Netz J. Hebbian-type stimulation during robot-assisted training in patients with stroke. Neurorehabil Neural Repair. 2011;25(7):645-655.

55. Hesse S, Werner C, Schonhardt EM, Bardeleben A, Jenrich W, Kirker SG. Combined transcranial direct current stimulation and robotassisted arm training in subacute stroke patients: a pilot study. Restor Neurol Neurosci. 2007;25(1):9-15.

56. Edwards DJ, Krebs HI, Rykman A, et al. Raised corticomotor excitability of M1 forearm area following anodal tDCS is sustained during robotic wrist therapy in chronic stroke. Restor Neurol Neurosci. 2009; 27(3):199-207.

57. Ochi M, Saeki S, Oda T, Matsushima Y, Hachisuka K. Effects of anodal and cathodal transcranial direct current stimulation combined with robotic therapy on severely affected arms in chronic stroke patients. J Rehabil Med. 2013;45(2):137-140.

58. Plautz EJ, Milliken GW, Nudo RJ. Effects of repetitive motor training on movement representations in adult squirrel monkeys: role of use versus learning. Neurobiol Learn Mem. 2000;74(1):27-55.

59. Basteris A, Sanguineti V. Toward 'optimal' schemes of robot assistance to facilitate motor skill learning. Conf Proc IEEE Eng Med Biol Soc. 2011;2011:2355-2358.
60. Morone G, Paolucci S, Mattia D, Pichiorri F, Tramontano M, Iosa M. The 3Ts of the new millennium neurorehabilitation gym: therapy, technology, translationality. Expert Rev Med Devices. 2016;13(9): 785-787.

61. Krishnan C, Ranganathan R, Dhaher YY, Rymer WZ. A pilot study on the feasibility of robot-aided leg motor training to facilitate active participation. PLoS One. 2013;8(10):e77370.

62. Perry J, Burnfield JM, Cabico LM. Gait Analysis: Normal and Pathological Function. Thorofare, NJ: SLACK; 2010.

63. Iosa M, Fusco A, Morone G, Paolucci S. Development and decline of upright gait stability. Front Aging Neurosci. 2014;6:14.

64. Iosa M, Zoccolillo L, Montesi M, Morelli D, Paolucci S, Fusco A. The brain's sense of walking: a study on the intertwine between locomotor imagery and internal locomotor models in healthy adults, typically developing children and children with cerebral palsy. Front Hum Neurosci. 2014;8:859.

65. Iosa M, Morone G, Bini F, Fusco A, Paolucci S, Marinozzi F. The connection between anthropometry and gait harmony unveiled through the lens of the golden ratio. Neurosci Lett. 2016;612:138-144.

66. Dzeladini F, van den Kieboom J, Ijspeert A. The contribution of a central pattern generator in a reflex-based neuromuscular model. Front Hum Neurosci. 2014;8:371
Neuropsychiatric Disease and Treatment

\section{Publish your work in this journal}

Neuropsychiatric Disease and Treatment is an international, peerreviewed journal of clinical therapeutics and pharmacology focusing on concise rapid reporting of clinical or pre-clinical studies on a range of neuropsychiatric and neurological disorders. This journal is indexed on PubMed Central, the 'PsycINFO' database and CAS,

\section{Dovepress}

and is the official journal of The International Neuropsychiatric Association (INA). The manuscript management system is completely online and includes a very quick and fair peer-review system, which is all easy to use. Visit http://www.dovepress.com/testimonials.php to read real quotes from published authors. 